\title{
In-Building Radio Propagation At 900 MHZ IN MULTI STORIED BUILDING
}

\author{
Deepak Gupta $^{1}$, Dr. Sunil Joshi ${ }^{2}$ \\ ${ }^{1}$ Department of Electronics, V.B. Polytechnic College, Udaipur, INDIA, \\ simptechedataone. in \\ ${ }^{2}$ Department of Electronics \& Communication, CTE, MPUAT, Udaipur, INDIA, \\ suniljoshi7erediffmail.com
}

\begin{abstract}
The proliferation of PCS has necessitated the complete characterization of radio channels existing inside buildings. The indoor radio channel differs from the conventional mobile radio channel in two aspects. First of all the distances taken in account are a lot small, and then the inconsistency of the environment is much larger for a smaller range of distance between transmitter and receiver. Indoor use of wireless systems poses one of the major design challenges, as indoor radio (RF) propagation is essentially a complex phenomenon. In this paper we will try to emphasis on this odd subject and will try to compute and place boundaries for use of wireless systems within buildings at $900 \mathrm{MHz}$. There are many good system design tools which have been developed solely for ground mobile cellular systems. However, no proper design tools have been developed for both ground mobile communication and in-building communications operated within one cellular system. As cellular systems are operated today, in-building communication is provided by transmitting radio signals from cell sites so that they penetrate the building walls to reach portable handsets inside buildings. In-building communication is harder to perform on the reverse link (portable-to-base link) than the forward link. Du to this it is difficult to mathematically put the model for all telecommunication systems in a single equation so many models coexist for different types of radio links for different situations. In this paper statically modelled is been explored. . The model rely on computing the median path loss for a link under a certain probability that the considered conditions will occur The modelling is done using simple measurements made especially for an intended communication system or spectrum allocation. This paper present radio signal propagation measurement and modelling at $900 \mathrm{MHz}$, within a Hotel building in the city of Udaipur (India).
\end{abstract}

\section{KEYWORDS}

Path Loss Exponent Received Signal Strength, Personal Communication System, Propagation Characteristic, Radio Propagation, Indoor Environment.

\section{Prologue To The fundamental of Radio Propagation}

The most fundamental sculpt of radio wave propagation is readily called "free space" radio wave propagation. As per this the radio waves radiate from a point source electromagnetic energy, travelling in all possible directions in a straight line, the radio energy varies in strength with range as range ${ }^{-2}$ rule (or as $20 \mathrm{~dB}$ per decade with increase in range). $[1,2]$

Such simple model is rarely available in the factual world radio propagation. The three basic mechanisms of radio propagation are attributed to diffraction, reflection and scattering. All of these three evident pieces of evidence cause radio signal distortions, fades, as well as propagation losses. For the situation outdoors, for instance with mobile units the movements over very small distance causes the signal strength fluctuations, as the complex signal is made up of a number of components of reflections, diffractions and scattering from various sources ("multipath signals"). The signal strength attenuation caused due to range are termed as "large scale" effects, while the signal fluctuations with movement are popularly termed as "small scale" effects. [2, 3] 
Indoors the situation is even worse. It is very difficult to design an "RF friendly" building that is free from multipath reflections, diffraction around sharp corners or scattering from wall, ceiling, or floor surfaces. For Indoors the straightforward free space model fails to report for the small and large scale fading that is practical in real world radio communication. Generally two kinds of multipath exist i.e. specular multipath due to discrete, coherent reflections from flat metal surfaces; and diffuse multipath due to diffuse scatterers and sources of diffraction. Equally both multipath are bad for radio communications. Diffuse multipath provide a type of background "noise" level of interference, while specular multipath in reality can cause complete radio signal outages and Electromagnetic "dead spots" inside a building. These dead spots take place for the reason of perfect, lossless reflections from smooth metal walls, ceilings and fixtures interfere with the signal coming directly from radiation sources. The dead spots subsist in 3 dimensional spaces inside the building. This problem is in particular not easy in underground tunnels, passageways, stair wells and in small covered rooms.[1,4]

\section{ELECTROMAGNETIC WAVE PROPAGATION INSIDE BUILDINGS}

Electromagnetic Wave Indoor Propagation Behaviour Electromagnetic wave propagation within the highly obstructed surroundings that is generally found inside buildings is mostly by an amalgamation of various mechanisms. The wave on a conducting obstacle induces currents in the obstacle, which are sequentially reradiated by means of further electromagnetic waves in relevant directions. This effect is in particular by wide-spread reinforced metal rods within building skeletons, metal drains and water piping, metal window frames, metallized window panes etc. The current can be guided along the whole obstacle in the form of bound waves even though of the impinging wave interacts only with a fraction of the obstacle. These can all very effectively guide the bound waves over surprisingly long distances and reradiate parts of the bound waves at the obstacle discontinuities and finally at the end of the obstacle. Even nonconducting dielectric obstacles can guide waves as dielectric waveguides.[5,6,7]

An indoor environment is usually very unpredictable, due to moving people, doors, windows, lifts, furniture and equipment. People have a particularly large influence on propagation waves at frequencies of mobile systems, because the human body is highly conductive. For example, a group of people filling a significant part of the cross section of a corridor can reduce the signal level behind them by a few tens of decibels. $[8,9,10]$

The main factors influencing the character of electromagnetic wave propagation are the type of building structure and the location of the antenna. There are two main types of principally different buildings from a wave propagation point of view. On the one hand, there are buildings with large open spaces; buildings with open offices and low plasterboard partitions, airport and railways terminals, shopping malls and large industrial assembly halls, for example. Wave propagation in such open spaces is naturally similar to propagation in free space, so that simple prediction models can be satisfactorily accurate. On the other hand, there are old office and residential buildings, usually with many small rooms and full of various pieces of equipment and furniture.[18]

The waveguiding effects of obstacles and their configurations (e.g., corridor, lift or air shaft) and obstacle shielding effects are naturally the dominant factors in indoor wave propagation. If the corridor waveguiding effect is moreover enhanced by locating an antenna in the corridor, the dominant radiated wave will be along the corridor almost regardless of the antenna radiation pattern. The wave propagation attenuation along a corridor can in this case be even less than in free space. The corridor wave distribution effect into adjacent rooms can be very beneficial for attaining the greatest possible coverage from a single antenna. If the coverage area is to be limited however, it is preferable to locate the antenna inside a room, due to the shielding effects of the walls. Wave propagation prediction can sometimes be simplified in Multi storied buildings by assuming wave propagation only in the horizontal plane i.e., only on they floor where the transmitter is located. This assumption is sometimes satisfactorily fulfilled, because 
the transmission loss of the floors is usually much higher than the loss of partitions on the floor.[15,20]

Indoor propagation can be strongly influenced not only by the structure of the building, but also by the surrounding environment. For example, adjacent buildings can be effective reflectors, which may encourage propagation between floors. [17]

Indoor propagation is a site-specific task and the choice of a suitable modelling approach should take this into account. The mean signal attenuation can be characterised by a signal decay factor, which equal to two corresponds to the wave power attenuation in free space, which is proportional to the second power of the distance from a transmitter. As the decay factor decreases, so does the signal attenuation, and vice versa. The signal decay factor along the corridor can usually be reduced from two. Many effects can within buildings, makes indoor propagation a very multifaceted and interesting process, which is not practicable to describe exactly in rigorous mathematic formulations. Quantifying indoor signal and its prediction is still therefore a kind of a secret art.[14,17]

\section{Indoor Radio Propagation Models}

The Radio Wave Propagation Model is an empirical mathematical method for the characterization of electromagnetic radio wave propagation as a function of distance, frequency and many other conditions. Such radio propagation models are based on large collections of data collected for the particular scenario of propagation. For any such model, the collection of data has to be very large to give enough room to all kind of situations, that can happen in that particular scenario. Like all other similar empirical models, radio propagation models do not show the exact behavior of a radio link, rather, they conclude only the most probable behavior of the link that may persist under the given specific condition. The path loss taken along any radio link serves as the prominent factor for characterization of radio link. Radio propagation models generally points on realization of the path loss with the secondary role of determining the area of coverage. [14]

Indoor radio propagation is also controlled by the same mechanism as that of outdoor. Reflection, diffraction, and scattering are the factors that influence the propagation. However, situation is much more changeable. For instance, signal levels vary deeply depending on whether inside doors are closed or open for a building. The position of mounting antennas also impacts large-scale propagation: Antennas placed at desk level in a office that is partitioned receive very much different signals than those put on the ceiling. In addition, the smaller propagation distances makes the situation more tricky to assure far-field radiation for all receiver positions and different types of antennas.[19]

\section{Indoor Propagation Modelling In Multi Storied Building OF UDAIPUR}

The measurements were carried out in a five story hotel building, which is located in urban areas in the city of Udaipur (India). The hotel has a variety of rooms linked to this hall with noline of-sight to the Tx. The location of the Tx was kept fixed in the hallway. Some rooms were abundantly, others sparsely furnished with wooden and metal furniture, shelves, and plants. This study in the Multi storied building of Udaipur throws light on the indoor propagation measurement at the frequency of $900 \mathrm{MHz} .[11-17]$

\subsection{Measurement System}

For the measurement campaign a special measurement device was used. The measurement system consists of the measurement transmitter and the measurement receiver with automated data collection. An AM modulated $900 \mathrm{MHz}$ transmitter was used. The movable antenna was kept at a walking velocity at a height of $1.5 \mathrm{~m}$ above the ground. 
International Journal of Distributed and Parallel Systems (IJDPS) Vol.2, No.6, November 2011
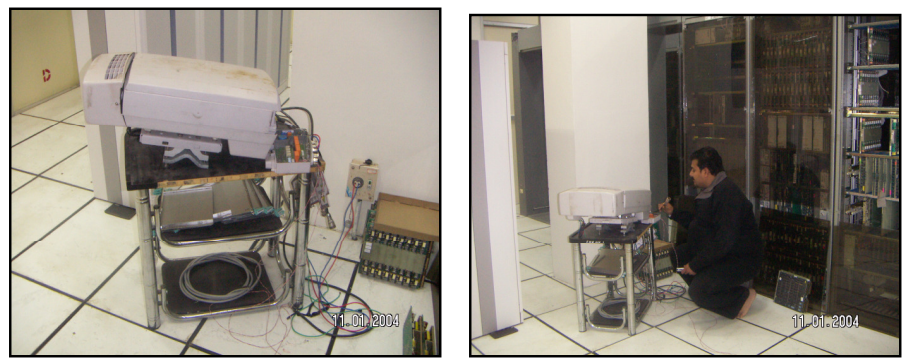

Figure 1. Transmitter

\section{Transmitter Parameters}

$>$ Brand: Ericsson

$>$ Frequency Band : 870-999 Mhz, 1 Mhz step

$>$ Frequency stablisation : PLL

$>$ Output Power : $30 \mathrm{dBm}, \pm 0.05 \mathrm{~dB}$

$>$ Modulation : $1 \mathrm{kHz}, \mathrm{AM}$

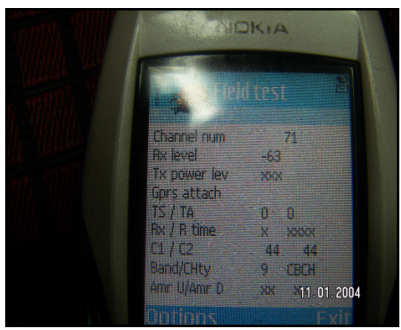

Figure 2. Receiver

\section{Receiver Parameters}

$>$ Brand: Nokia

$>$ Software : Field Test

$>$ I/P Signal Range : -30 to $-110 \mathrm{dBm}$

$>$ Resolution : 1dB Min

\subsection{Measurement Campaign at Different Locations}

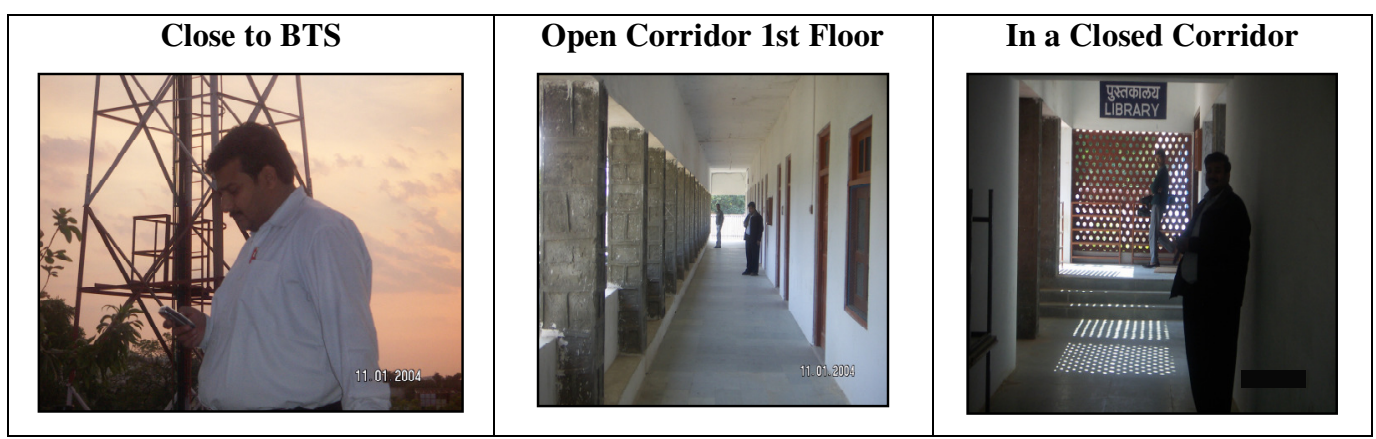

Figure 3. Measurement Campaign

\section{Study OF d ${ }^{\mathrm{n}}$ Path Loss Model (One Slope Model):}

Large-scale fading analysis is concerned with predicting the mean signal strength as a function of transmitter-receiver (T-R) separation distance (d) over T-R separations of hundreds, thousands, or millions of meters. In this section, the widely-employed and easy-to-use $\mathrm{d}^{\mathrm{n}}$ model is presented, where $d$ represents the T-R separation distance and relates to path loss in terms of an empirical path loss exponent, n. $[4,20]$ 
This $\mathrm{d}^{\mathrm{n}}$ path loss model is usually used to forecast the power move between a transmitter and a receiver. This model also considers the diminish in energy density caused by the electro magnetic wave due to distribution, as well as the energy loss due to the interface of the electromagnetic wave with the broadcast surroundings. "Path loss" is the expression used to enumerate the difference (in $\mathrm{dB}$ ) between the transmitted power, $\mathrm{P}_{\mathrm{t}}$ (in $\mathrm{dBm}$ ), and received power, $\mathrm{P}_{\mathrm{r}}$ (in $\mathrm{dBm}$ ).

The $\mathrm{d}^{\mathrm{n}}$ model predicts that the mean path loss, PL(d), measured in $\mathrm{dB}$, at a T-R separation $\mathrm{d}$ will be $[21,22]$

$$
\operatorname{PL}(\mathrm{d})=\operatorname{PL}\left(\mathrm{d}_{0}\right)+10 \mathrm{n} \log _{10}\left(\mathrm{~d} / \mathrm{d}_{0}\right) \quad(\mathrm{dB})
$$

Here $\operatorname{PL}\left(\mathrm{d}_{0}\right)$ is the mean path loss measured in $\mathrm{dB}$ at close-in at a reference $\mathrm{d}_{0}$ distance. $\mathrm{n}$ is a empirical number i.e. the "path loss exponent". We recognize that $n=2$, the path loss is identical as free space path loss exponent, at this the received signals go down of by $20 \mathrm{~dB}$ per decade with increase in distance. Reference $\mathrm{d}_{0}$ distance is chosen to be in the far field of the antenna, at points where the propagation can be assumed to be close to the transmitter such that multipath and diffraction are insignificant also the link is in the region of that of free-space. Classically, $\mathrm{d}_{0}$ is selected to be $1 \mathrm{~m}$ for indoor environments and $100 \mathrm{~m}$ or $1 \mathrm{~km}$ for outdoor situation. The free space distance must be in region of far field from the antenna, which is also linked to the bodily size and frequency of the antenna. $\operatorname{PL}\left(\mathrm{d}_{0}\right)$ can be calculated or approximated by the subsequent formula: $[4,20,23,24]$

$$
\operatorname{PL}\left(\mathrm{d}_{0}\right)=20 \log _{10}\left(\frac{4 \pi \mathrm{d}_{0}}{\lambda}\right)
$$

Here $\lambda=\mathrm{c} / \mathrm{f}$ is the wavelength.

The path loss exponent ' $n$ ' is an observed constant that is frequently calculated. It can also be theoretically derived in some situations. We will at this point calculate ' $n$ ' for a Multi storied building of Udaipur.

\subsection{Path Loss Exponent and Standard Deviation Calculation for Multi storied Building Based On First Model (One Slope)}

Table 1. Path Loss Calculation For First Model (One-Slope Model)

\begin{tabular}{|c|c|c|c|c|c|c|}
\hline $\begin{array}{c}\text { Distance } \\
(\mathbf{m})\end{array}$ & $\begin{array}{c}\text { Path Loss } \\
(\mathbf{d B}) \\
\mathbf{n = 1}\end{array}$ & $\begin{array}{c}\text { Path Loss } \\
(\mathbf{d B}) \\
\mathbf{n = 2}\end{array}$ & $\begin{array}{c}\text { Path Loss } \\
(\mathbf{d B}) \\
\mathbf{n = 3}\end{array}$ & $\begin{array}{c}\text { Path Loss } \\
(\mathbf{d B}) \\
\mathbf{n = 4}\end{array}$ & $\begin{array}{c}\text { Path Loss } \\
(\mathbf{d B}) \\
\mathbf{n}=\mathbf{5}\end{array}$ & $\begin{array}{c}\text { Path Loss } \\
(\mathbf{d B}) \\
\mathbf{n}=\mathbf{6}\end{array}$ \\
\hline 1 & 30 & 30 & 30 & 30 & 30 & 30 \\
\hline 2 & 33 & 36 & 39 & 42 & 45 & 48 \\
\hline 3 & 35 & 40 & 44 & 49 & 54 & 59 \\
\hline 4 & 36 & 42 & 48 & 54 & 60 & 66 \\
\hline 5 & 37 & 44 & 51 & 58 & 65 & 72 \\
\hline 6 & 38 & 46 & 53 & 61 & 69 & 77 \\
\hline 7 & 38 & 47 & 55 & 64 & 72 & 81 \\
\hline 8 & 39 & 48 & 57 & 66 & 75 & 84 \\
\hline 9 & 40 & 49 & 59 & 68 & 78 & 87 \\
\hline 10 & 40 & 50 & 60 & 70 & 80 & 90 \\
\hline 11 & 40 & 51 & 61 & 72 & 82 & 92 \\
\hline 12 & 41 & 52 & 62 & 73 & 84 & 95 \\
\hline
\end{tabular}


International Journal of Distributed and Parallel Systems (IJDPS) Vol.2, No.6, November 2011

\begin{tabular}{|c|c|c|c|c|c|c|}
$\begin{array}{c}\text { Distance } \\
(\mathbf{m})\end{array}$ & $\begin{array}{c}\text { Path Loss } \\
(\mathbf{d B}) \\
\mathbf{n = 1}\end{array}$ & $\begin{array}{c}\text { Path Loss } \\
(\mathbf{d B}) \\
\mathbf{n = 2}\end{array}$ & $\begin{array}{c}\text { Path Loss } \\
(\mathbf{d B}) \\
\mathbf{n = 3}\end{array}$ & $\begin{array}{c}\text { Path Loss } \\
(\mathbf{d B}) \\
\mathbf{n = 4}\end{array}$ & $\begin{array}{c}\text { Path Loss } \\
(\mathbf{d B}) \\
\mathbf{n}=\mathbf{5}\end{array}$ & $\begin{array}{c}\text { Path Loss } \\
(\mathbf{d B}) \\
\mathbf{n}=\mathbf{6}\end{array}$ \\
\hline 13 & 41 & 52 & 63 & 75 & 86 & 97 \\
\hline 14 & 41 & 53 & 64 & 76 & 87 & 99 \\
\hline 15 & 42 & 54 & 65 & 77 & 89 & 101 \\
\hline 16 & 42 & 54 & 66 & 78 & 90 & 102 \\
\hline 17 & 42 & 55 & 67 & 79 & 92 & 104 \\
\hline 18 & 43 & 55 & 68 & 80 & 93 & 105 \\
\hline 19 & 43 & 56 & 68 & 81 & 94 & 107 \\
\hline 20 & 43 & 56 & 69 & 82 & 95 & 108 \\
\hline 21 & 43 & 56 & 70 & 83 & 96 & 109 \\
\hline 22 & 43 & 57 & 70 & 84 & 97 & 111 \\
\hline 23 & 44 & 57 & 71 & 84 & 98 & 112 \\
\hline 24 & 44 & 58 & 71 & 85 & 99 & 113 \\
\hline 25 & 44 & 58 & 72 & 86 & 100 & 114 \\
\hline 26 & 44 & 58 & 72 & 87 & 101 & 115 \\
\hline 27 & 44 & 59 & 73 & 87 & 102 & 116 \\
\hline 28 & 44 & 59 & 73 & 88 & 102 & 117 \\
\hline 29 & 45 & 59 & 74 & 88 & 103 & 118 \\
\hline 30 & 45 & 60 & 74 & 89 & 104 & 119 \\
\hline
\end{tabular}

n : Path Loss Exponent

Table 2. Path Loss Exponent \& Standard Deviation for Same Floor

\begin{tabular}{|c|c|c|c|c|}
\hline $\begin{array}{c}\text { Distance } \\
(\mathbf{m})\end{array}$ & $\begin{array}{l}\text { Path Loss (dB) } \\
\text { Same Floor } \\
\end{array}$ & $\begin{array}{c}\text { Path Loss } \\
\text { Exponent n }\end{array}$ & $\begin{array}{c}\text { Average Path } \\
\text { Exponent n }\end{array}$ & $\begin{array}{c}\text { Standard } \\
\text { Deviation } \sigma(\mathrm{dB})\end{array}$ \\
\hline 5 & 50 & 2.86 & \multirow{6}{*}{2.77} & \multirow{6}{*}{5.4} \\
\hline 10 & 55 & 2.50 & & \\
\hline 15 & 62 & 2.72 & & \\
\hline 20 & 67 & 2.84 & & \\
\hline 25 & 70 & 2.86 & & \\
\hline 30 & 72 & 2.84 & & \\
\hline
\end{tabular}

Table 3. Path Loss Exponent \& Standard Deviation For Through One Floor

\begin{tabular}{|c|c|c|c|c|}
\hline $\begin{array}{c}\text { Distance } \\
(\mathbf{m})\end{array}$ & $\begin{array}{c}\text { Path Loss (dB) } \\
\text { Same Floor }\end{array}$ & $\begin{array}{c}\text { Path Loss } \\
\text { Exponent n }\end{array}$ & $\begin{array}{c}\text { Average Path } \\
\text { Exponent n }\end{array}$ & $\begin{array}{c}\text { Standard } \\
\text { Deviation } \boldsymbol{\sigma}(\mathbf{d B})\end{array}$ \\
\hline 5 & 60 & 4.29 & & \\
\cline { 1 - 3 } 10 & 68 & 3.80 & & \multirow{2}{*}{4} \\
\cline { 1 - 2 } 15 & 78 & 4.08 & \multirow{2}{*}{6.5} \\
\hline 20 & 85 & 4.23 & & \\
\hline 25 & 90 & 4.29 & & \\
\hline 30 & 96 & 4.47 & & \\
\hline
\end{tabular}


International Journal of Distributed and Parallel Systems (IJDPS) Vol.2, No.6, November 2011

Table 4. Path Loss Exponent \& Standard Deviation through Two Floors

\begin{tabular}{|c|c|c|c|c|}
\hline $\begin{array}{c}\begin{array}{c}\text { Distance } \\
(\mathbf{m})\end{array} \\
\end{array}$ & $\begin{array}{c}\text { Path Loss (dB) } \\
\text { Same Floor } \\
\end{array}$ & $\begin{array}{c}\text { Path Loss } \\
\text { Exponent n }\end{array}$ & $\begin{array}{l}\text { Average Path } \\
\text { Exponent n }\end{array}$ & $\begin{array}{c}\text { Standard } \\
\text { Deviation } \sigma(\mathrm{dB})\end{array}$ \\
\hline 5 & 69 & 5.58 & \multirow{6}{*}{5.07} & \multirow{6}{*}{6.8} \\
\hline 10 & 81 & 5.10 & & \\
\hline 15 & 88 & 4.93 & & \\
\hline 20 & 94 & 4.92 & & \\
\hline 25 & 99 & 4.94 & & \\
\hline 30 & 103 & 4.94 & & \\
\hline
\end{tabular}

Table 5. Path Loss Exponent \& Standard Deviation through Three Floors

\begin{tabular}{|c|c|c|c|c|}
\hline $\begin{array}{l}\text { Distance } \\
\text { (m) }\end{array}$ & $\begin{array}{l}\text { Path Loss (dB) } \\
\text { Same Floor }\end{array}$ & $\begin{array}{c}\text { Path Loss } \\
\text { Exponent n }\end{array}$ & $\begin{array}{l}\text { Average Path } \\
\text { Exponent n }\end{array}$ & $\begin{array}{c}\text { Standard } \\
\text { Deviation } \sigma(\mathrm{dB})\end{array}$ \\
\hline 5 & 70 & 5.72 & \multirow{6}{*}{5.28} & \multirow[t]{6}{*}{ 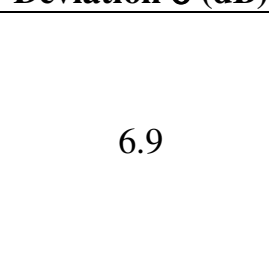 } \\
\hline 10 & 82 & 5.20 & & \\
\hline 15 & 91 & 5.19 & & \\
\hline 20 & 97 & 5.15 & & \\
\hline 25 & 103 & 5.22 & & \\
\hline 30 & 107 & 5.21 & & \\
\hline
\end{tabular}

PATH LOSS AS A FUNCTION OF DISTANCE

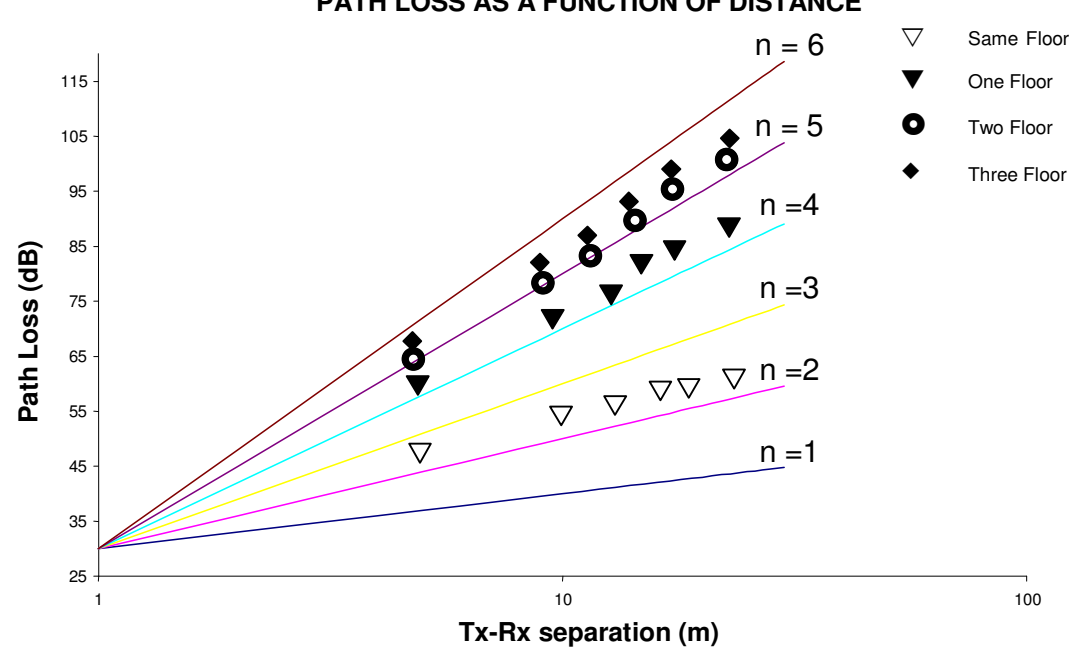

Figure 4. Path Loss as a function of distance (Typical values of $\mathrm{n}$ for different floors)

\section{Multi-Floor Model -A}

For the multi-floor propagation modelling the basic empirical modelling approach with linear dependence of the floor attenuation is used:[15,20-24]

$$
\mathrm{L}(\mathrm{d})=\mathrm{L}_{0}+10 \mathrm{n} \log \mathrm{d}+\mathrm{kF}_{1}
$$

Where $\quad \mathrm{L}(\mathrm{d})$ Path loss in the distance $\mathrm{d}[\mathrm{m}]$ from the transmitter $[\mathrm{dB}]$

$\mathrm{L}_{0} \quad$ Attenuation in reference distance $1 \mathrm{~m}$ obtained as a free space propagation $[\mathrm{dB}]$

n Path-loss exponent

$\mathrm{k} \quad$ Number of floors between transmitter and receiver antennas

$\mathrm{F}_{1} \quad$ Single-floor propagation attenuation (floor loss factor) [dB]. 
International Journal of Distributed and Parallel Systems (IJDPS) Vol.2, No.6, November 2011

\section{Multi-Floor Model -B}

The non-linear dependence of the floor attenuation can also be given by another relation. [15,20-24]

$$
\mathrm{L}(\mathrm{d})=\mathrm{L}_{0}+10 \mathrm{n} \log \mathrm{d}+\mathrm{F}_{\mathrm{k}}
$$

Where $\quad \mathrm{L}(\mathrm{d})$ Path loss in the distance $\mathrm{d}[\mathrm{m}]$ from the transmitter $[\mathrm{dB}]$

$\mathrm{L}_{0} \quad$ Attenuation in reference distance $1 \mathrm{~m}$ obtained as free space propagation [dB]

n Path-loss exponent

$\mathrm{k} \quad$ Number of floors between transmitter and receiver antennas

$\mathrm{F}_{\mathrm{k}} \quad$ Propagation attenuation through $\mathrm{k}$ floors between transmitter and receiver antennas $[\mathrm{dB}]$

\section{Result Multi Floor Building (Model A \& B)}

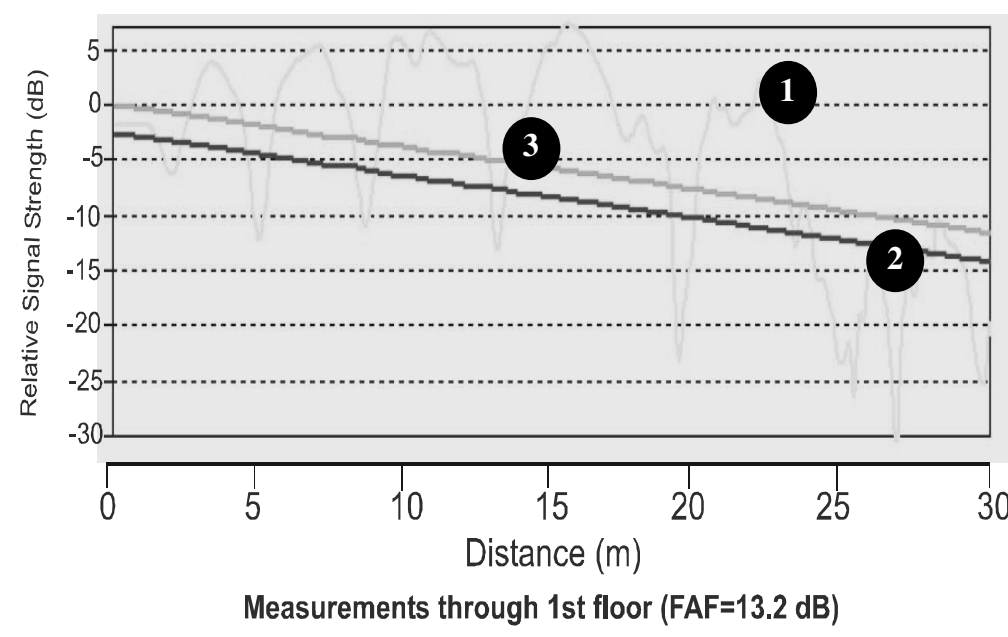

1. Measurement

2. Model (A)

3. Model (B)

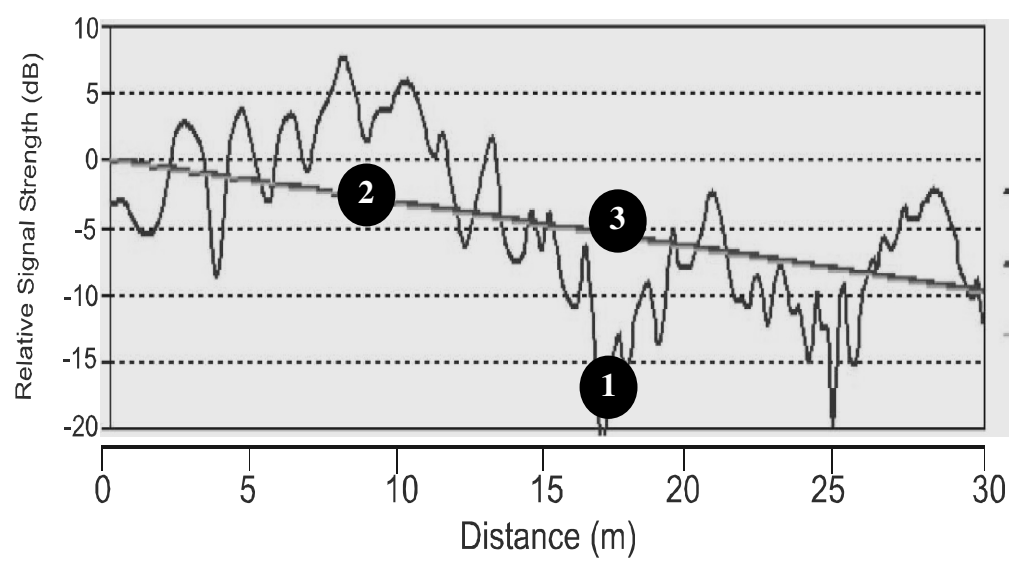

1. Measurement

2. Model (A)

3. Model (B)

Measurements through 2nd floor (FAF=18.1 dB) 

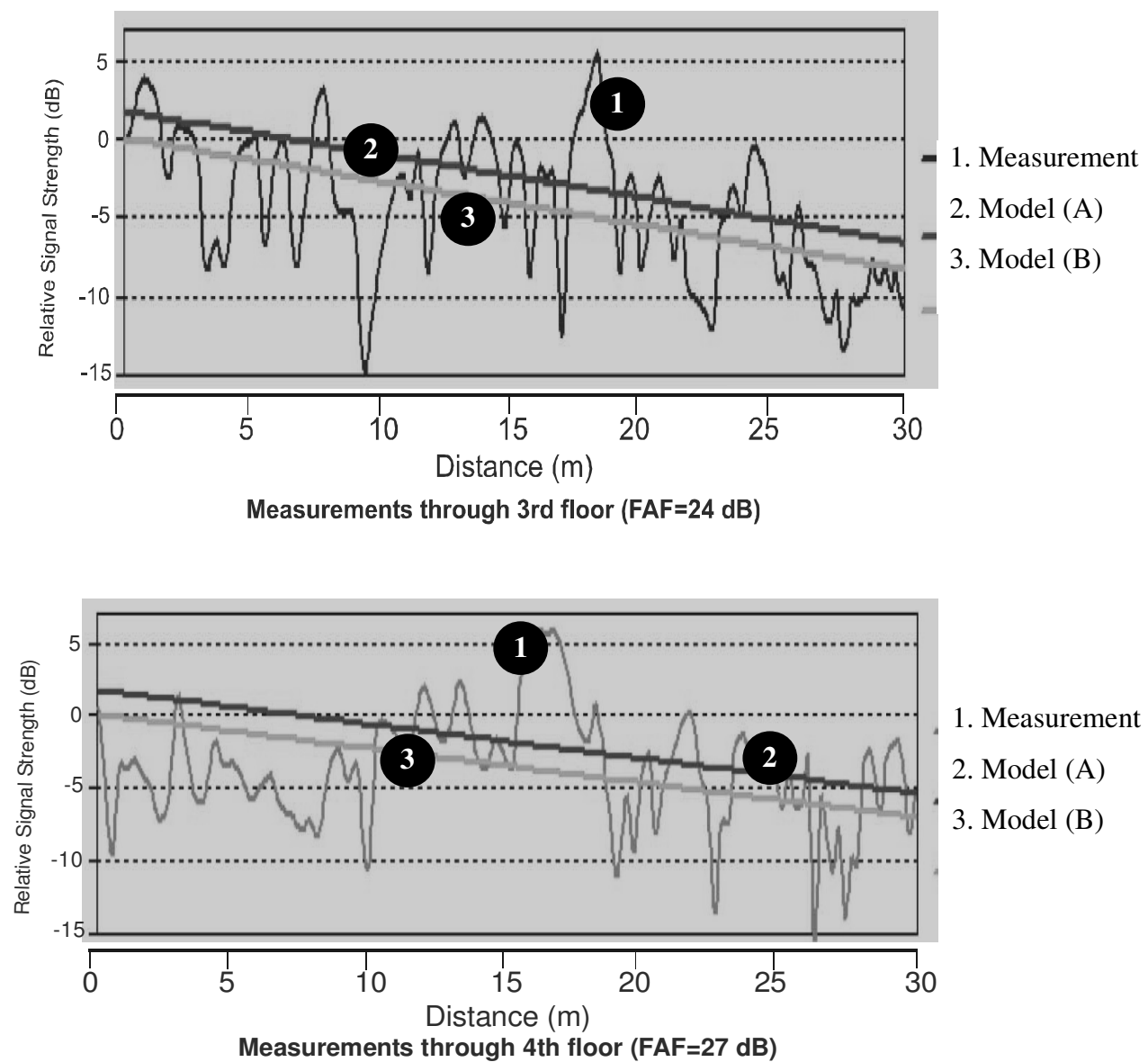

Figure 5. Measurement results of Multi-Floor Model A \& B

\section{Conclusions}

Our effort was to derive $\mathrm{n}$ and $\mathrm{F}$ for both models. Figure shows the structure of the Building (Hotel Dayal, at Udaipur) with the transmitter location and receiver paths in each floor. All the paths were same lengths of $30 \mathrm{~m}$ in the corridor with no other major obstacles between the transmitter and receiver.

It can be easily observed that a satisfactory correctness can be derived using straightforward model (A) with linear floor loss factor. Path loss exponent ' $n$ ' demonstrates a prominent waveguide effect as in corridors. The measurements were periodically done a number of times in different time slots of the day. Derived model standard deviations and parameters were varying within $1 \mathrm{~dB}$.

Table 6. Model Parameters and Standard Deviations

\begin{tabular}{|c|c|c|c|c|c|c|}
\hline Model & $\mathbf{n}$ & $\mathbf{F}_{\mathbf{1}}$ & $\mathbf{F}_{\mathbf{2}}$ & $\mathbf{F}_{\mathbf{3}}$ & $\mathbf{F}_{\mathbf{4}}$ & Standard Deviations \\
\hline A & 1.9 & 35.1 & & & & 5.5 \\
\hline B & 1.8 & 13.2 & 18.1 & 24 & 27 & 5.0 \\
\hline
\end{tabular}


International Journal of Distributed and Parallel Systems (IJDPS) Vol.2, No.6, November 2011

\section{REFERENCES}

[1] Molkdar, D., "Review on Radio Propagation into and Within buildings," IEE Proceedings, Vol.138, No.1, pp.61-73, February 1991.

[2] Hashemi, H., "The Indoor Radio Propagation Channel," Proceedings of IEEE, Vol. 81, No.7, pp, 943-968, July 1993.

[3] Cox, D.C., Murray, R.R., and Norris, A.W., "Measurements of $800 \mathrm{MHz}$ Radio Transmission into Building with Metallic Walls. "Bell Systems Technical Journal, Vol. 62, No. 9, pp. 26952717, November 1983.

[4] Rappaport, T.S., "Characterization of UHF Multipath Radio Channels in Factory Buildings," IEEE Transactions on Antennas and Propagation, Vol. 37, No.8, p.1058-1069, August 1989.

[5] T.S. Rappaport, Wireless Communications: Principles and Practice, Prentice Hall PTR, Prentice-Hall, Inc., A Simon \& Schuster Company, Upper Saddle River, New Jersey 07458, 1996.

[6] T.K. Sarkar, Z. Ji, K. Kim, A. Medouri, and M. Salazar-Palma, "A Survey of Various and Propagation Models for Mobile Communication," IEEE Antennas and Propagation Magazine, vol. 45, no. 3, June 2003,pp. 51-82.

[7] M. Matsunaga, T. Matsunaga, and T. Sueyoshi, "An analysis of the effects of wall shapes on electromagnetic waves propagating around buildings," Proceedings of the 39th Microwave Conference, pp. 990 - 993, Sept. 2009

[8] M. Fakharzadeh et al., "The Effect of Human Body on Indoor Radio Wave Propagation at 57-64 GHz," Proceedings of the 2009 IEEE Antennas and Propagation Society International Symposium, pp. 1 - 4, June 2009.

[9] M. Nishi et al., "Human detection system using UHF band terrestrial TV receiving waves," Proceedings of the 2006 IEEE Antennas and Propagation Society International Symposium, pp. 3097 - 3100, July 2006.

[10] M. Ghaddar et al., "A Conducting Cylinder for Modeling Human Body Presence in Indoor Propagation Channel," IEEE Trans. on Antennas and Propagation, vol. 55, no. 11, pp. 3099 3103, Nov. 2007.

[11] P. Hájek: "Measurement transmitter $900 \mathrm{MHz,"} \mathrm{Diploma} \mathrm{Thesis,} \mathrm{Czech} \mathrm{Technical} \mathrm{University} \mathrm{in}$ Prague, Department of Electromagnetic Field, Prague 1997.

[12] D. Dedek: "Measurement receiver 900 MHz," Diploma Thesis, Czech Technical University in Prague, Department of Electromagnetic Field, Prague 1999.

[13] A.J. Motley and J.M.P. Keenan: "Personal Communication Radio Coverage in Buildings at 900 MHz and $1700 \mathrm{MHz}$,” IEE Electronics Letters, vol. 24, no. 12, pp. 763-764, 1989.

[14] Y.S. Scott and T.S. Rappaport, "914 MHz Path Loss Prediction Models for Indoor Wireless Communications in Multifloored Buildings," IEEE Trans. on Antennas and Propagation, vol. 40, no. 2, pp. 207 - 217, February 1992.

[15] Indoor Propagation Modelling In Multi Storied Buildings In Prague by Pavel Pechač, Martin Klepal, Miloš Mazánek

[16] F.C. Owen and C.D. Pudney, "In-Building Propagation at $900 \mathrm{MHz}$ and $1650 \mathrm{MHz}$ for Digital Cordless Telephones," ICAP '89 University of Warwick, vol. 2., pp. 276 - 280, IEE, April 1989.

[17] P. Pechač: "Propagation of Electromagnetic Waves for Mobile and Personal Communications," Doctoral Thesis, Czech Technical University in Prague, Department of Electromagnetic Field, Prague 1998

[18] HASLETT, C. Essentials of Radio Wave Propagation. Cambridge (UK): Cambridge University Press, 2008. 
[19] KLEPAL, M. Novel Approach To Indoor Electromagnetic Wave Propagation Modeling. PhD thesis. Prague: Czech Technical University In Prague, 2003.

[20] Wireless communication's, principles \& practices 2c, Theodore S. Rappaport Chapter 4.

[21] Morrow, R. K., and Rappaport, T. S. "Getting In," Wireless Review, pp. 42-44, March 1, 2000, http://www.wirelessreview.com/issues/2000/00301/feat24.htm.

[22] Skidomore, R., Rappaport, T. S., and Abbott, A. L., "Interactive Coverage Region and System Design Simulation for Wireless Communication Systems in Multifloored Environments: SMT Plus," IEEE International Confrence on Universal Personal Communications, Cambridge. MA, September 29-October 2, 1996, pp. 646-650.

[23] Rappaport, T. S., "Isolating Interference," Wireless Review, pp. 33-35, May 1, 2000. http://www.wirelessreview.com/issues/2000/00501/feat23.htm.

[24] Devasirvatham, D. J., Krain. M. J., and Rappaport, D. A., "Radio Propagation Measurements at $850 \mathrm{MHz}, 1.7 \mathrm{GHz}$, and 4.0 GHz Inside Two Dissimilar Office Buildings," Electronics Letters, Vol. 26, No. 7, pp. 445-447, 1990.

\section{Authors}

Deepak Gupta was born in Jodhpur, India in 1973. He received B.E. (Hons) in 1995 in Electronics \& Communication Engineering and M.E. (Gold Medallist) in Digital Communication from MBM Engineering College, JNV University, Jodhpur (India). He joined as lecturer in Electronics in Vidya Bhawan Polytechnic College, Udaipur in 1996; presently he is Head of Electronics Department in the Institute. He is currently pursing Ph.D. in "Channel Optimization Techniques in Urban Outdoor and Indoor Indian Environment using Multiple Input Multiple-Output Technology".

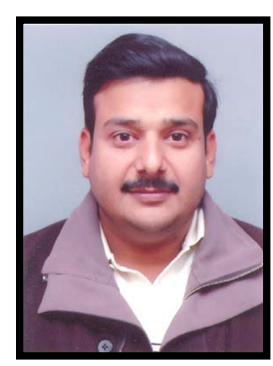

Dr. Sunil Joshi was born in Jodhpur, India in 1967. He received B.E. (Hons) in 1990 in Electronics \& Communication Engineering and M.E. in Year 2000 in Digital Communication from MBM Engineering College, JNV University, Jodhpur (India). He taught at various capacities in Diploma and Degree level technical Institutions. He did his Ph.D. in Year 2006 in "Propagation Studies of Millimeter Waves" from Microwave Systems Group Department of Electronics \& Communication Engineering Mailviya National Institute of Technology, University of Rajasthan, Jaipur. Presently he is Head of Electronics \& Communication Department in the College of Technology \& Engineering, Maharana Pratap University of Agriculture \& Technology, Udaipur.

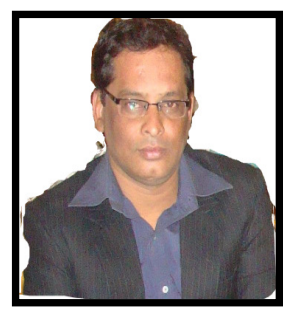

